\title{
Pengaruh Waktu Tahan Proses Pack Carburizing Baja AISI 3115 dengan Menggunakan Calcium Carbonat dan Batubara Sub Bituminous dan Mendapatkan Perlakuan Panas Quenching Media Pendingin Air
}

\author{
Dhimas Satria*, Ipick Setiawan, Imron Rosyadi, Erny Listijorini, Haryadi, Rina Lusiani, Ariesmunandar \\ Jurusan Teknik Mesin, Fakultas Teknik, Universitas Sultan Ageng Tirtayasa \\ Jl. Jenderal Sudirman Km 3, Kotabumi, Kec. Purwakarta, Kota Cilegon, Banten 42435 \\ *E-mail: dhimas@untirta.ac.id
}

\begin{abstract}
Material development in the industrial world is increasingly demanding for engineering of these materials so that a strong and resilient material is produced according to needs. One method to improve the physical properties of the material is by carburizing or carburizing. The research method used in this study is the carburization process followed by rapid quenching to increase its hardness so that the metal surface becomes more wear resistant, then adds energizer or calcium carbonate activating material and sub bituminous coal which will accelerate the formation of low CO gas. This study aims to find a good heat treatment solution on AISI 3115 steel then heat treatment is carried out at a temperature variation of $750^{\circ} \mathrm{C}, 850^{\circ} \mathrm{C}$, and $950^{\circ} \mathrm{C}$. Followed by rapid cooling (quenching) using liquid in the form of water in a container, which is expected to increase the hardness of AISI 3115 steel. The results of the study are caruburation process followed by rapid heat treatment and cooling, and the addition of calcium carbonate and sub-bituminous coal activating agents. The effect of increasing the level of hardness in low carbon steel AISI 3115. The higher the temperature in the heat treatment process, the hardness increases and the value of carbon level also increases with height based on high temperature parameters, due to increased carbon value in steel using carbon in the form of subituminous coal with binder in the form of calcium carbonate. The function of calcium carbonate is also as a medium to accelerate the carburizing process. The effect of the best temperature is at a temperature of $950^{\circ} \mathrm{C}$. In this study, the highest hardness value was 38.14. and has a late corrosion rate of 2.86 mpy and the best microstructure photo is found at $850^{\circ} \mathrm{C}$ because light colored ferrite in steel indicates that steel is not hard, while dark colored pearlite is hard because the black dot is more than the point white, the best hardness value can be obtained at $850^{\circ} \mathrm{C}$.
\end{abstract}

Keywords: Carburizing, Calcium Carbonat, Heat Treatment, Quenching

\section{Abstrak}

Perkembangan material di dunia industri semakin menuntut untuk rekayasa terhadap material tersebut sehingga dihasilkan material yang kuat dan ulet sesuai dengan kebutuhan. Salah satu metode untuk meningkatkan sifat fisik dari material adalah dengan carburizing atau proses karburisasi. Metode penelitian yang digunakan dalam penelitian ini adalah proses karburisasi yang diikuti dengan perlakuan pendinginan cepat (quenching) untuk meningkatkan kekerasannya sehingga permukaan logam menjadi lebih tahan aus, kemudian menambahkan energizer atau bahan pengaktif kalsium karbonat dan batu bara sub bituminous yang akan mempercepat terbentuknya gas CO rendah. Penelitian ini bertujuan mencari solusi perlakuan panas yang baik pada baja AISI 3115 maka dilakukan perlakuan panas (heat treatment) pada variasi suhu $750^{\circ} \mathrm{C}, 850^{\circ} \mathrm{C}, 950^{\circ} \mathrm{C}$. Disusul dengan pendinginan cepat menggunakan cairan berupa air dalam suatu wadah, yang diharapkan dapat meningkatkan kekerasan baja AISI 3115. Hasil penelitian adalah proses karburasi yang diikuti proses perlakuan panas dan pendinginan cepat, serta penambahan bahan pengaktif kalsium karbonat dan batubara sub bituminous mempunyai pengaruh untuk meningkatkan tingkat kekerasan pada baja karbon rendah AISI 3115. Semakin tinggi temperatur pada proses heat treatment maka kekerasan semakin meningkat dan nilai tingkat karbon juga ikut meningkat berdasarkan parameter suhu yang tinggi, dikarenakan peningkatan nilai karbon pada baja menggunakan karbon berupa batubara subituminus dengan pengikat berupa calsium karbonat. Fungsi dari calsium karbonat juga sebagai media untuk mempercepat proses karburasi. Pengaruh temperatur terbaik terdapat pada suhu $950^{\circ} \mathrm{C}$. Pada penelitian ini didapatkan nilai kekerasan tertinggi sebesar 38,14. dan memiliki laju korosi terlambat dengan nilai 2,86 mpy dan foto struktur mikro terbaik terdapat pada suhu $850^{\circ} \mathrm{C}$ dikarenakan ferrit yang bewarna terang pada baja menandakan bahwa baja bersifat tidak keras, sedangkan pearlit yang bewarna gelap bersifat keras karena titik hitam lebih banyak dibandingkan titik putih maka nilai kekerasan terbaik di dapat pada suhu $850^{\circ} \mathrm{C}$.

Kata kunci: Karburasi, Calcium Carbonat, Perlakuan Panas, Quenching 


\section{Pendahuluan}

Seiring dengan perkembangan dunia industri yang semakin maju, tentunya pembangunan membutuhkan suatu bahan logam yang cukup baik, pada sifat fisik maupun mekanis, sebagai bahan utama operasional atau sebagai bahan baku produksinya [1]. Pada komponen mesin, sering dijumpai suatu bahan yang diperlukan kekerasan dan keuletannya, misalnya roda gigi, banyak dilakukan pengembangan oleh peneliti untuk menghasilkan roda gigi yang baik, hal ini di karenakan seringnya roda gigi mengalami kerusakan saat terjadi gesekan dan tekanan yang dihasilkan. Sehingga diinginkan suatu konstruksi bahan yang keras dan juga ulet pada intinya untuk mencegah kerusakan. Kemudian agar memperoleh hasil yang baik, komponen-komponen dari mesin mesin tersebut selanjutnya diberi perlakuan panas yang bertujuan merubah sifat sifat logam berupa fisis dan mekanisnya [2][3]. Media pendingin [4] dan juga suhu yang digunakan perlu di perhatikan agar tujuan untuk memberikan sifat mekanis pada baja ini tercapai [5][6][7].

Carburizing adalah sebuah proses penambahan unsur karbon pada permukaan logam dengan cara difusi untuk meningkatkan sifat fisis dan mekanisnya [8]. Pada umumnya proses karburisasi diikuti dengan perlakuan pendinginan cepat (quenching) untuk meningkatkan kekerasannya sehingga permukaan logam menjadi lebih tahan aus. Metode proses ini dibedakan menurut media karburasinya yaitu gas, cair dan padat. Proses karburisasi telah dikembangkan dan diteliti sedemikian rupa menggunakan teknologi canggih, misalnya metode karburisasi cair sistem vakum. Namun demikian, karburisasi padat yang merupakan metode yang paling sederhana masih digunakan pada industri-industri kecil di Indonesia. Misalnya untuk penyepuhan pisau yang memanfaatkan arang baterai bekas. Berbagai usaha telah dilakukan untuk memperbaiki proses karburisasi padat dengan menambahkan energizer atau bahan pengaktif seperti barium karbonat, natirum karbonat dan kalsium karbonat. Bahan pengaktif tersebut akan mempercepat terbentuknya gas CO rendah.

Soffiyudin [9] melakukan penelitian tentang carburizing yaitu menggunakan media arang batok kelapa, dimana hasil dalam penelitian tersebut, proses carburizing akan menghasilkan sifat fisik, yaitu kekerasan pada material baja AISI 4140 akan meningkat. Penelitian ini merupakan pengembangan dari penelitian yang dilakukan oleh Soffiyudin dengan memberikan perlakuan panas (heat treatment) pada variasi suhu $750^{\circ} \mathrm{C}, 850^{\circ} \mathrm{C}, 950^{\circ} \mathrm{C}$, disusul dengan pendinginan cepat (quenching) menggunakan cairan berupa air dalam suatu wadah, dengan tujuan diharapkan dapat meningkatkan kekerasan dari baja AISI 3115 [10].

\section{Metode penelitian}

\subsection{Material}

Material yang digunakan dalam penelitian ini antara lain: Baja karbon rendah AISI 3115, serbuk batubara karbon subbituminus, dan calsium carbonat. Pada pengujian pada penelitian ini menggunakan baja AISI 3115. Baja ini merupakan baja karbon rendah dengan kadar karbon (C) 0,14-0,19\%. Kemudian dibentuk spesimen sesuai standar pengujian yang akan dilakukan.

\subsection{Preparasi Spesimen}

Dimensi sampel pengujian kekerasan dan laju korosi menggunakan tabung silindris dengan tebal $15 \mathrm{~mm}$. Sampel dikelompokan sesuai dengan proses pengujian yang akan dilakukan pada material tersebut, seperti terlihat pada Tabel 1 berikut.

Tabel 1. Perincian sampel pengujian

\begin{tabular}{|c|c|c|c|c|c|}
\hline \multirow[b]{2}{*}{ Jumlah (buah) } & \multirow[b]{2}{*}{ Heat treatment } & \multicolumn{4}{|c|}{ Jenis Pengujian } \\
\hline & & $\begin{array}{c}\text { Komposisi kimia } \\
\text { (buah) }\end{array}$ & $\begin{array}{c}\text { Struktur mikro } \\
\text { (buah) }\end{array}$ & $\begin{array}{c}\text { Kekerasan } \\
\text { (Titik) }\end{array}$ & $\begin{array}{l}\text { Laju korosi } \\
\text { (buah) }\end{array}$ \\
\hline 3 & $750^{\circ} \mathrm{C}$ & 1 & 1 & 5 & 1 \\
\hline 3 & $850^{\circ} \mathrm{C}$ & 1 & 1 & 5 & 1 \\
\hline 3 & $950^{\circ} \mathrm{C}$ & 1 & 1 & 5 & 1 \\
\hline $\begin{array}{l}\text { Non heat treatment } \\
3 \text { buah }\end{array}$ & Suhu kamar & 1 & 1 & 5 & 1 \\
\hline
\end{tabular}

\section{Hasil Dan Pembahasan}

\subsection{Komposisi Kimia}

Uji komposisi kimia di lakukan untuk mengetahui persentase unsur kimia yang terkandung dalam spesimen. Baik setelah perlakuan panas yang kemudian di quenching menggunakan air maupun sebelum mendapatkan perlakuan panas. Berdasarkan hasil uji komposisi diketahui baja AISI 3115 yang termasuk dalam baja karbon rendah (low carbon steel) mengandung kurang dari 0,30\%. Baja AISI 3115 sendiri memiliki kadar karbon 0,15\%. Komposisi yang terdapat pada 
baja sangat berpengaruh terhadap sifat mekanis baja seprti kekerasan, keuletan dan tingkat korosi. Pengujian komposisi diperoleh data seperti terlihat pada Tabel 2 .

Hasil dari pengujian ini menunjukan bahwa kandungan tembaga yang terdapat pada baja AISI 3115 semakin meningkat seiring naiknya suhu perlakuan panas. Pada raw material mengandung carbon $0,1525 \%$. Namun meningkat jauh pada sampel yang mengalami perlakuan panas dan proses karburisasi pada suhu 750oc yang mengandung carbon sebesar $0,4649 \%$. Sedangkan untuk temperature $850^{\circ} \mathrm{c}$ mengalami peningkatan kandungan yang tidak siknifikan di bandingkan dengan $750^{\circ} \mathrm{c}$ sebesar 0,5071 . Untuk temperature $950^{\circ} \mathrm{c}$ mengalami peningkatan kandungan carbon lebih banyak dari specimen-spesimen yang mengalami perlakuan panas sebelumnya yaitu sebesar 0,5753. Setelah baja mengalami perlakuan panas kemudian di quenching menggunakan cairan berupa air. Tidak hanya terjadi peningkatan kandungan karbon pada baja namun terjadi pelapisan pada sekeliling permukaan baja yang dapat mengurang laju korosi pada spesimen.

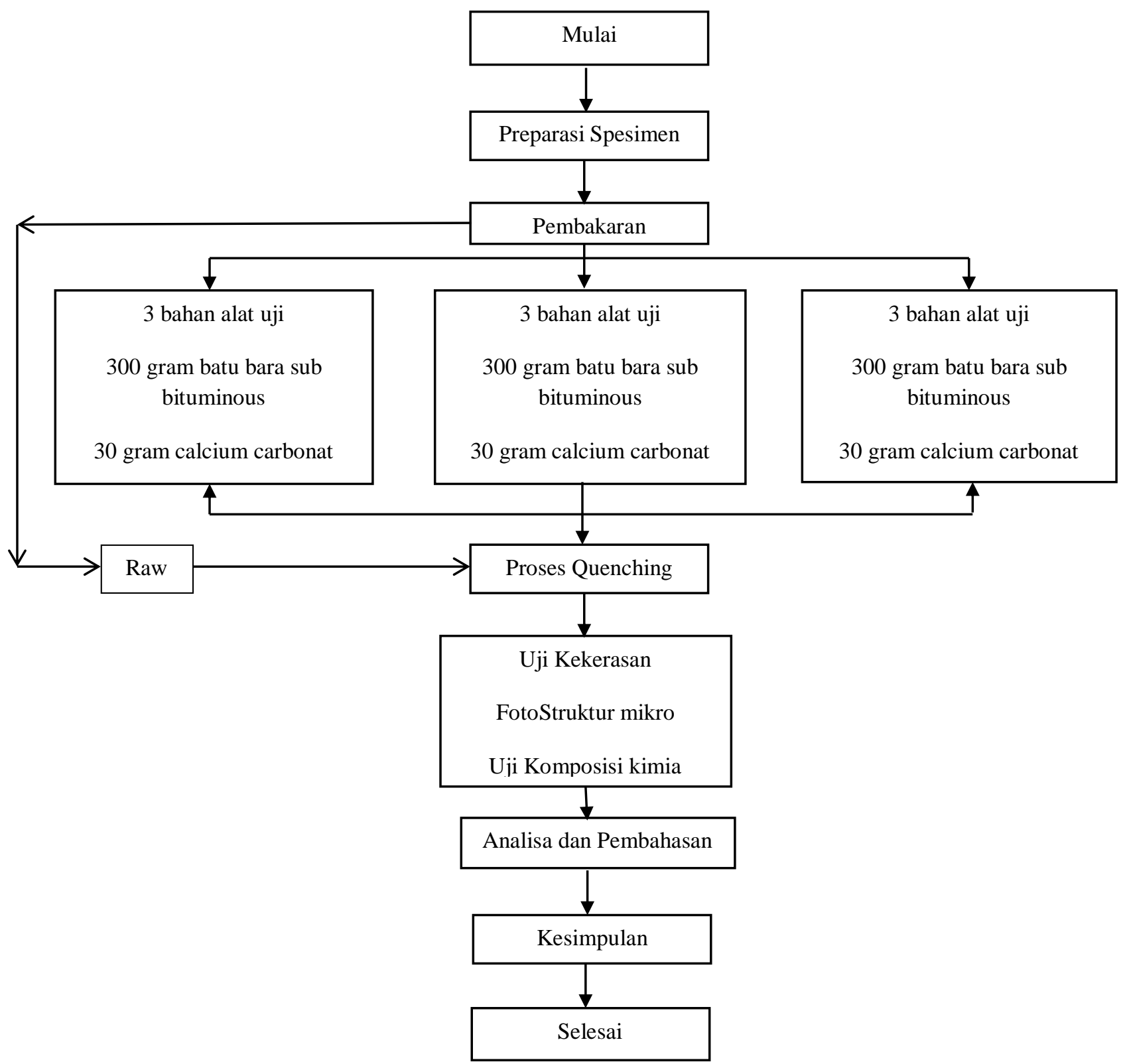

Gambar 1. Diagram alir penelitian 
Tabel 2. Hasil uji komposisi kimia

\begin{tabular}{|c|c|c|c|c|c|}
\hline \multirow[b]{2}{*}{ Parameter } & \multicolumn{4}{|c|}{ Hasil } & \multirow[b]{2}{*}{ Satuan } \\
\hline & $\begin{array}{c}\text { Raw } \\
\text { Material } \\
\end{array}$ & $\begin{array}{c}\text { Suhu } \\
7_{50}^{\circ} \mathrm{C} \\
\end{array}$ & $\begin{array}{c}\text { Suhu } \\
850^{\circ} \mathrm{C} \\
\end{array}$ & $\begin{array}{l}\text { Suhu } \\
950^{\circ} \mathrm{C} \\
\end{array}$ & \\
\hline $\mathrm{C}$ & 0,1525 & 0,4649 & 0,5071 & 0,5753 & $\%$ \\
\hline $\mathrm{Si}$ & 0,1974 & 0,1980 & 0,2023 & 0,1953 & $\%$ \\
\hline $\mathrm{Mn}$ & 0,4551 & 0,4634 & 0,4675 & 0,4551 & $\%$ \\
\hline $\mathrm{P}$ & 0,0283 & 0,0300 & 0,0301 & 0,0276 & $\%$ \\
\hline $\mathrm{S}$ & 0,0166 & 0,0178 & 0,0201 & 0,0183 & $\%$ \\
\hline $\mathrm{Cr}$ & 0,0999 & 0,1010 & 0,1016 & 0,0999 & $\%$ \\
\hline $\mathrm{Ni}$ & 0,0368 & 0,0376 & 0,0374 & 0,0370 & $\%$ \\
\hline Mo & 0,0020 & 0,0022 & 0,0024 & 0,0020 & $\%$ \\
\hline $\mathrm{V}$ & 0,0016 & 0,0016 & 0,0018 & 0,0016 & $\%$ \\
\hline $\mathrm{Cu}$ & 0,0887 & 0.0881 & 0,0903 & 0,0875 & $\%$ \\
\hline $\mathrm{Al}$ & 0,0051 & 0.0050 & 0,0049 & 0,0050 & $\%$ \\
\hline $\mathrm{N}$ & 0,0052 & 0,0054 & 0,0053 & 0,0057 & $\%$ \\
\hline
\end{tabular}

\subsection{Pengujian struktur mikro}

Pengujian struktur mikro pada penelitian ini bertujuan untuk melihat struktur dan karakteristik dari material. Struktur mikro yang dihasilkan setelah proses hardening akan menentukan sifat-sifat mekanis baja, terutama kekerasan, karena salah satu tujuan utama dari proses hardening adalah untuk meningkatkan kekerasan baja. Peningkatan kekerasan ini diperoleh melalui pembentukan struktur martensit sebanyak mungkin melalui quenching ataupun pendinginan air. Semakin banyak sturktur martensit yang terbentuk maka akan semakin tinggi kekerasan baja. Oleh karena itu pengamatan struktur mikro baja setelah proses hardening perlu dilakukan untuk mengetahui sejauh mana efektifitas proses hardening yang telah dilakukan dalam penelitian ini.

Foto struktur mikro pada logam dapat dilihat dengan menggunakan mikroskop optic cahaya untuk mengambil gambar struktur dengan 100 kali pembesaran dan 200 kali pembesaran.

Tabel 3. Perincian foto struktur mikro

\begin{tabular}{ccc}
\hline Sampel & Proses Heat Treatment & Waktu Tahan (Menit) \\
\hline Raw Material & - & - \\
\hline 1 & Tp $750^{\circ} \mathrm{C}$ & 24 \\
\hline 2 & Tp $850^{\circ} \mathrm{C}$ & 24 \\
\hline 3 & Tp $950^{\circ} \mathrm{C}$ & 24 \\
\hline
\end{tabular}

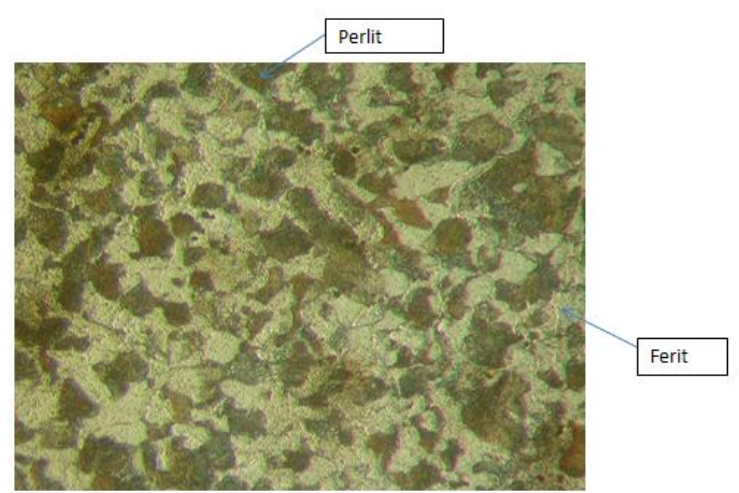

Gambar 2. Sampel foto struktur mikro pemesaran 200x (raw material)

Gambar 2 merupakan gambar struktur mikro dari sampel baja karbon rendah AISI 3115 dengan pembesaran 200 kali. Sampel ini belum mengalami perlakuan panas, kekerasannya adalah 14,8 hrc. Sampel ini mempunyai struktrur ferit besar yang bewarna terang dan lebih mendominasi dibandingkan dengan perlit yang bewarna gelap.struktur ferrit yang 
bewarna terang pada baja, menandakan bahwa baja bersifat lunak namun ulet dan perlit menandakan baja bersifat kuat dan cukup keras pada raw material ini tidak terdapat martensit yang berwarna garis gelap.

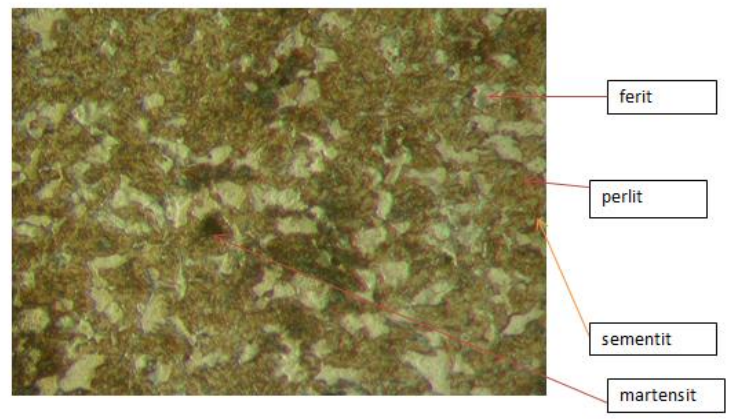

Gambar 3. Sampel foto struktur mikro pembesaran 200x $\left(\mathrm{T} 750{ }^{\circ} \mathrm{c}\right)$

Dari Gambar 3 dapat diambil kesimpulan mengenai gambar struktur mikro dari sampel baja karbon rendah AISI 3115 dengan pembesaran 200 kali pengambilan di titik yang sama. Setelah mengalami proses heat treatment pada temperature $750^{\circ} \mathrm{C}$ dengan waktu tahan 63 menit dan di quenching menggunakan air. Menjadikan struktur yang terbentuk ferit dengan bentuk bergaris tidak beraturan dan sedikit. Sedangkan jumlah perlit banyak pada sampel $750^{\circ} \mathrm{C}$ menandakan bahwa sifat sampel ini keras dan cukup kuat. Serta pada sampel ini terdapat kandungan struktur martensit dalam jumlah sangat sidikit dikarenakan biasanya martensit sangat banyak diatas $800^{\circ} \mathrm{C}$ dikarenakan sifat martensit adalah keras dan getas. Sedangkan sementit mempunyai sifat paling keras cenderung rapuh. Pada sampel ini jumlah sementit dan martensit sangat sedikit hampir tidak ada Karena proses heat treatment tidak mencapai temperature austenite yang menjadikan sampel ini cukup keras namun ulet.

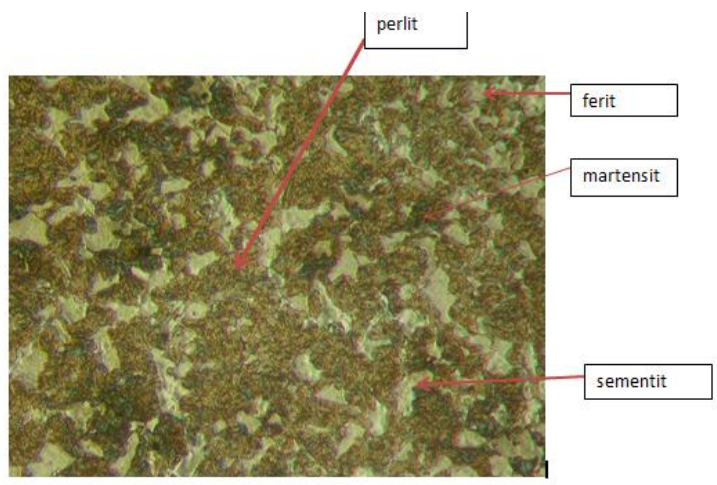

Gambar 4. Sampel foto struktur mikro pembesaran 200x $\left(\mathrm{T} 850^{\circ} \mathrm{c}\right)$

Gambar 4 adalah struktur mikro dari sampel baja karbon rendah AISI 3115 dengan pembesaran 200 kali pengambilan di tempat yang sama. Setelah mengalami proses heat treatment pada temperature $850{ }^{\circ} \mathrm{C}$ waktu tahan 24 menit dan di quenching menggunakan air. Menjadikan struktur yang terbentuk ferrit dan terdapat sedikit bainit. Bainit terbentuk bila austenite didinginkan dengan cepat hingga mencapai temperature tertentu. Transformasi bainit ini disebabkan sebagian karena proses difusi dan sebagian lagi karena proses tanpa difusi. Sehingga material ini mempunyai sifat yang cenderung keras.

Gambar 5 adalah struktur mikro dari sampel baja karbon rendah AISI 3115 dengan pembesaran 200 kali pengambilan di titik yang sama. Setelah mengalami proses heat treatmenet pada temperature $950^{\circ} \mathrm{C}$ dengan waktu tahan 63 menit dan di quenching menggunakan air. Menjadikan struktur yang terbentuk ferit dengan bentuk bergaris tidak beraturan dan sedikit. Sedangkan jumlah perlit sangat sedikit pada sampel $950^{\circ} \mathrm{C}$ menandakan bahwa sifat sampel ini keras dan cukup ulet hanya sedikit. Serta pada sampel ini terdapat kandungan struktur martensit dalam jumlah yang sangat banyak dikarenakan biasanya martensit sangat banyak diatas $800^{\circ} \mathrm{C}$ dikarenakan sifat martensit adalah keras dan getas sedangkan sementit mempunyai sifat paling keras cenderung rapuh. Pada sampel ini martensit sangat banyak dikarenakan proses heat treatment mencapai temperatur austenite, yang menjadikan sampel ini keras dan getas. Sedangkan sementit sangat sedikit cenderung tidak ada pada sampel $950^{\circ} \mathrm{C}$ dikarenakan sifat sementit ini adalah keras cenderung rapuh pada sampel ini sifat keras dan cenderung rapuh tidak ada tapi sifat keras dan getas sangat banyak dikarenakan jumlah martensit yang melimpah dibandingkan dengan jumlah perlit. Jadi sifat material pada sampel $950^{\circ} \mathrm{C}$ ini adalah keras dan sangat getas ini menunjukan bahwa sampel ini cederung bisa mengalami patah karena sampel ini tidak keras cenderung ulet. 


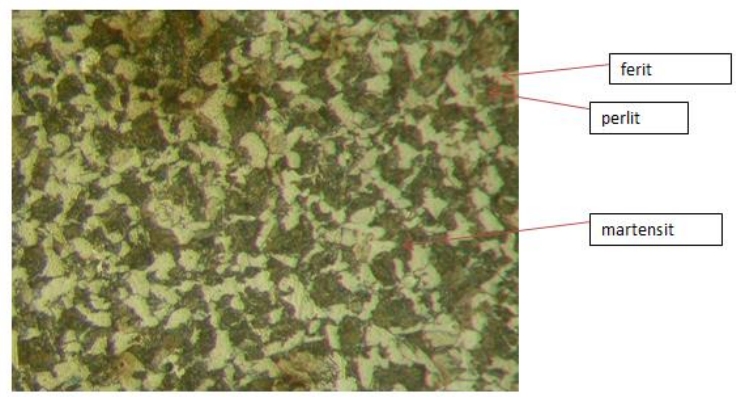

Gambar 5. Sampel foto struktur mikro pembesaran 200x $\left(\mathrm{T} 950^{\circ} \mathrm{c}\right)$

\subsection{Hasil uji kekerasan}

Tujuan dari pengujian kekerasan adalah untuk mengetahui tingkat kekerasan baja karbon pada raw material dan yang di capai akibat penahanan selama 24 menit dengan berbagai variasi temperature yaitu $750^{\circ} \mathrm{C}, 850^{\circ} \mathrm{C}, 950^{\circ} \mathrm{C}$, yang di lakukan dengan pendinginan cepat (quenching) menggunakan cairan berupa air. Pengujian kekerasan dilakukan dengan menggunakan metode Rockwell dengan skala hrc, dan pembebanan atau biasa di sebut dengan test blok yang diberikan sebesar 39 kgf. Setiap satu sampel di kenai 5 titik injakan dipermukaan baja karbon, sehingga menghasilkan data nilai kekerasan pada sampel tersebut. Hasil nilai kekerasan yang didapatkan dapat dilihat pada Tabel 4.

Tabel 4. Hasil pengujian kekerasan baja AISI 3115

\begin{tabular}{ccccccc}
\hline \multirow{2}{*}{ Spesimen } & \multicolumn{3}{c}{ Hasil Kekerasan (HRC) } & \multicolumn{2}{c}{ Rata-rata } \\
\cline { 2 - 6 } & 1 & 2 & 3 & 4 & 5 & (HRC) \\
\hline Raw Material & 12,7 & 8,0 & 4,3 & 8,6 & 11,7 & 9,06 \\
\hline Temperatur $750^{\circ} \mathrm{C}$ & 16,5 & 16,7 & 16,3 & 17,4 & 16,0 & 16,58 \\
\hline Temperatur $850^{\circ} \mathrm{C}$ & 23,9 & 23,7 & 24,2 & 30,1 & 32,0 & 26,3 \\
\hline Temperatur $950^{\circ} \mathrm{C}$ & 32,7 & 37,1 & 37,6 & 42.2 & 41,3 & 38,14 \\
\hline
\end{tabular}

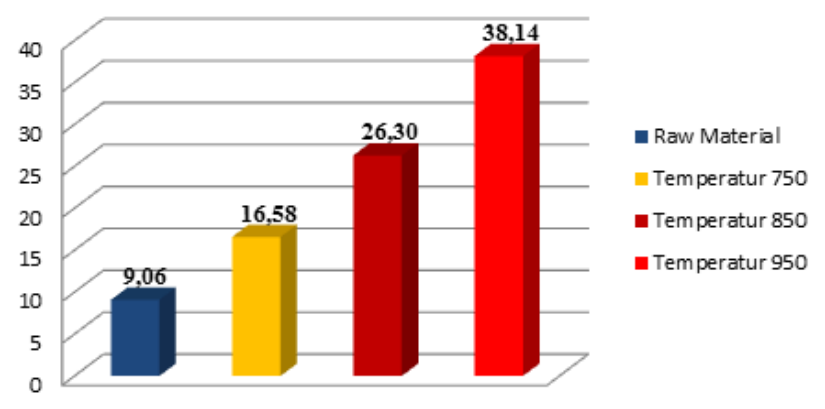

Gambar 6. Grafik nilai rata-rata uji kekerasan (Rockwell)

Pada Tabel 4 dan Gambar 6 menunjukan grafik hasil pengujian kekerasan raw material dan variasi temperatur pada baja AISI 3115. Untuk sampel raw material mendapatkan nilai kekerasan rata-rata 9,06 HRC. Nilai ini digunakan sebagai pembanding bagi baja yang sudah dilakukan proses heat treatment dan quenching. Untuk sampel ke-2 diberi perlakuan panas dengan temperature $750{ }^{\circ} \mathrm{C}$, kemudian di quenching dengan cairan air. Mempunyai nilai kekerasan rata rata 16,58 HRC. Mengalami peningkatan sebesar 49 dari sampel ke-1. Peningkatan kekerasan terjadi akibat perlakuan panas pada sampel ke-2 yang menyebabkan menambahnya struktur perlit. Sebagaimanapun telah diketahui bahwa perlit adalah lapisan ferrit dan sementit dengan komposisi sekitar $88 \%$ ferrit dan $12 \%$ sementit. Sehingga nilai kekerasan pada sampel ke-2 meningkat dengan menambahnya struktur pearlit ini.

Sedangkan untuk sampel ke-3 yang diberi perlakuan dengan temperature $850^{\circ} \mathrm{C}$ mempunyai nilai kekerasan rata-rata yang lebih tinggi dari sampel ke-2 yaitu 26,30 HRC. Sampel ini mengalami peningkatan sebesar 164,18 dari sampel ke1. Nilai tersebut meningkat dikarenakan temperature perlakuan panas yang diberikan pada sampel ke-3 lebih tinggi daripada sampe yang ke-2. Struktur yang terbentuk pada sampel ke-3 yaitu struktur mikro berbentuk ferrit dan terdapat baini. Foto struktur mikro dengan temperature 850 dapat dilihat pada Gambar 5. Untuk sampel ke-4 diberikan perlakuan panas dengan temperatur lebih tinggi daripada sampel ke-2 dan ke-3 yaitu $950{ }^{\circ} \mathrm{C}$ dan nilai kekerasan sebesar 38,14 . Peningkatan kekerasan terjadi akibat perlakuan panas pada sampel ke-4 yang menyebabkan terbentuknya struktur martensit yang sangat banyak. Struktur martensit terjadi pada saat temperatur austenite yang sudah tercukupi kemudian dibdinginkan dengan cepat sekali sehingga temperatur di atas pembentukan perlit. 
Dari pengujian kekerasan ini dapat diambil kesimpulan bahwa sampel raw material memiliki nilai kekerasan yang rendah dengan nilai kekerasan sebesar 9,06 raw material mempunyai struktur ferrit yang bewarna terang lebih mendoninasi dibandingkan struktru perlit yang bewarna gelap. Strutur ferrit pada baja menandakan baja bersifat tidak keras namun ulet. Pada sampel ke-2 ke-3 ke-4, mengalami perlakuan panas dengan temperature yang semakin tinggi yaitu pada temperature $750{ }^{\circ} \mathrm{C}, 850^{\circ} \mathrm{C}$ dan $950^{\circ} \mathrm{C}$. Nilai kekerasan sampel dari masing masing perlakuan panas semakin keras dengan struktur mikro yang berbeda beda.

\subsection{Hasil uji laju korosi}

Pengujian korosi dilakukan dengan metode imersi. Dalam pengujian ini standar pengujian yang dipakai adalah ASTM G31 menggunakan larutan garam dengan konsentrasi sebesar 5\%. Hasil pengujian ini diapat di tunjukan dalam Tabel 5.

Tabel 5. Hasil pengujian laju korosi

\begin{tabular}{ccc}
\hline No. & Sampel & Laju Korosi (mpy) \\
\hline 1 & Raw Material & 5,64 \\
\hline 2 & Temperatur $750^{\circ} \mathrm{C}$ & 4,52 \\
\hline 3 & Temperatur $850^{\circ} \mathrm{C}$ & 3,62 \\
\hline 4 & Temperatur $950^{\circ} \mathrm{C}$ & 1,89 \\
\hline
\end{tabular}

Hasil pengujian laju korosi diatas dapat digambarkan dalam sebuah grafik seperti pada Gambar 7.

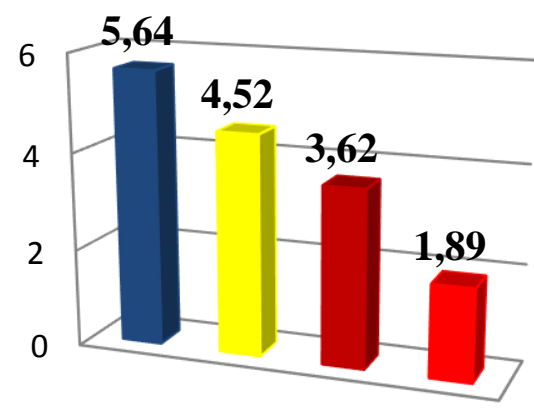

\author{
Raw Material \\ Temperatur $750^{\circ} \mathrm{C}$ \\ Temperatur $850^{\circ} \mathrm{C}$ \\ Temperatur $950^{\circ} \mathrm{C}$
}

Gambar 7. Grafik nilai uji korosi (metode iniersi)

Hasil dari uji korosi dari masing-masing sampel menunjukkan adanya perbedaan laju korosi. Dari sampel raw material, mempunyai laju korosi 5,64 mpy. Sampel ke-2 perlakuan panas pada temperatur $750^{\circ} \mathrm{C}$ dan di quenching dengan air mempunyai laju korosi sebesar 4,52 mpy dari raw material. Untuk sampel ke-3 mengalami perlakuan panas pada temperatur $850^{\circ} \mathrm{C}$. kemudian di quenching dengan cairan air mempunyai laju korosi sebesar 3,12 mpy dan pada temperatur $850^{\circ} \mathrm{C}$ mengalami penurunan juga sebasar $31,83 \%$ dari raw material. Sedangkan untuk sampel ke-4 mengalami perlakuan panas yang sama yaitu di quenching menggunakan cairan air yaitu sebesar 950 . Pada sampel ini mempunyai laju kororsi yang sangat rendah dari sample yang lain yaitu 1,89 mpy mengalami penurunan sebesar $35,87 \%$ dari sampel raw material. Laju korosi degan nilai tertinggi didapat pada sampel raw material dengan nilai sebesar 5,64 mpy. Dan laju korosi dengan nilai terendah didapat pada sampel ke-4 pada temperatur $950^{\circ} \mathrm{C}$ degan nilai laju korosi sebesar 1,89 pada raw material mempunyai nilai laju korosi tertinggi ini dikarenakan sampel raw material mempunyai struktur BCC yang terdiri dari ferrit dan perlit. Maka ruang antar atom pada baja tidak rapat, banyak celah yang menyebabkan larutan garam akan mudah masuk ke dalam celah-celah yang menyebabkan larutan garam akan mudah masuk kedalam celah-celah sampel.sehingga akan mucah terjadinya korosi pada sampel raw material. Sedangkan sampel yang mengalami proses quenching mengalami penurunan laju korosi degan temperatur yang semakin tinggi dan laju korosi yang semakin rendah, karena, sampel yang mendapat perlakuan panas memiliki kerapatan antara atomnya, sehingga larutan garam hanya mengkorosi permukaan sampel. Selain itu, sampel yang mendapatkan perlakuan panas lalu di quenching degan cairan air. Terlihat jelas bahwa unsur karbon yang melapisi pada perbukaan dan sekeliling baja dan lapisan carbon tersebut dapat juga memperlambat laju korosi.

\section{Kesimpulan}

Setelah spesimen diberikan perlakuan panas pada suhu yang berbeda kemudian di perlakuan karburisasi dan quenching. Maka pada penelitian ini dapat diambil beberapa kesimpulan sebagai berikut: Cairan berupa air sebagai media pendingin quenching mempunyai pengaruh untuk meningkatkan tingkat kekerasan pada baja karbon rendah AISI 3115. Di karenakan proses quenching ini mempercepat proses kekerasan pada baja yang sudah dilakukan proses heat treatment. Semakin tinggi temperatur pada proses heat treatment maka kekerasan semakin meningkat. Hal ini dikarenakan mengalami perlakuan panas. Dan nilai tingkat karbon juga ikut meningkat dengan tinggi berdasarkan 
parameter suhu yang tinggi, dikarenakan peningkatan nilai karbon pada baja menggunakan carbon berupa batubara subituminus dengan pengikat berupa calsium karbonat. Fungsi dari calsium karbonat juga sebagai media untuk mempercepat proses karburasi. Pengaruh temperatur terbaik terdapat pada suhu $950^{\circ} \mathrm{C}$. Pada penelitian ini didapatkan nilai kekerasan tertinggi sebesar 38,14 . dan memiliki laju korosi terlambat dengan nilai 2,86 mpy dan foto struktur mikro terbaik terdapat pada suhu $850^{\circ} \mathrm{C}$ di karenakan ferrit yang bewarna terang pada baja menandakan bahwa baja bersifat tidak keras sedangkan pearlit yang bewarna gelap bersifat keras karena titik hitam lebih banyak dibandingkan titik putih maka nilai kekerasan terbaik di dapat pada suhu $850^{\circ} \mathrm{C}$

\section{Ucapan Terima Kasih}

Penulis mengucapkan terimakasih kepada Fakultas Teknik Untirta yang telah mendukung terkait dana untuk terselanggaranya penelitian ini.

\section{Daftar Pustaka}

[1] A. Schonmetz, K. Gruber, Pengetahuan Bahan dalam Pengerjaan Logam. Bandung: Penerbit Angkasa, 1994.

[2] C.R. Brooks, Principles of the Heat Treatment of Plain Carbon and Low Alloy Steels. ASM International, Materials Park, 1996.

[3] R. Shallman, R. Bishop, Metalurgi Fisik Modern dan Rekayasa Material. Jakarta: Penerbit Erlangga, 2000.

[4] Karmin, M. Ginting, “Analisis Peningkatan Kekerasan Baja Amutit Menggunakan Media Pendingin Dromus,” J. Austenit Jur. Tek. Mesin, vol. 4, no. 1, pp. 1-7, 2012.

[5] H. Anver, Introduction to Physical Metallurgy, 2nd editio. New York: McGraw-Hill International editions, 1974.

[6] F. Husain, Y. Setiyorni, "Pengaruh Variasi Temperatur Austenisasi pasa Proses Heat Treatment Quenching Terhadap Sifat Mekanik dan Struktur Mikro Friction wedge AISI 1340,” J. Tek. Pomits, vol. 2, no. 2, pp. 324-329, 2013.

[7] G. Totten, C. Bates, N. Clinton, Handbook of Quenchant and Quenching Technology. USA: ASM International, 1993.

[8] B. Selcuk, R. Ipek, and M. Karamis, "Study on Behaviour of Carburized, Carbonitrided and Borided AISI 1020 5115 Steel,” J. Mater. Process. Technol., vol. 141, pp. 189-196, 2003.

[9] A. Soffiyudin, "Pengaruh Suhu Carburizing Menggunakan Media Arang Batok Kelapa Terhadap Kekerasan dan Haus pada Roda Gigi Baja AISI 4140," Universitas Negeri Semarang, Semarang, 2007.

[10] H. McGannnon, Ed., The Making Shaping and Treating of Steel, 9th Editio. Pittsburgh: United States Steel Corporation, 1971. 